\title{
Geological Mining Industry Information Platform Construction
}

\author{
Zhe WANG, Li SUN, Jian SUN \\ Qinhuangdao Institute of Technology, 066100, Qinhuangdao, Hebei,China \\ email: 123515821@qq.com
}

\begin{abstract}
Keywords: Internet; Geological mining industry; Information platform; Ore power inquiry
Abstract. Along with the computer technology fast development, the office automation technology progresses by leaps and bounds. At present our country geology and the mining industry domain entered the fast development stage, the geological prospecting, the mining industry development and the correlation industry become our country economy development the foundation prop. In order to get rid of the office the fetter, constructs based on the Internet information service platform, advances the geological mining industry informationization advancement vigorously, Realization information sharing, may enhance the office efficiency, the frugal fund, this is enhances the profession technology, the management and the service level way that must be taken. This paper is main discussed geology mining industry information platform plan, design, development and application.
\end{abstract}

\section{Introduction}

Our country resources supply insufficiency and the economical high speed development contradiction, the geological prospecting, the mineral resource development and the management receives the country attaches great importance. At present our country geology and the mining industry domain entered the fast development stage, the geological prospecting, the mining industry development and the correlation industry become our country economy development the foundation prop. This profession technology and the administrative personnel are facing the unprecedented opportunity and the challenge. get rid of the office the fetter, constructs based on the Internet information service platform, advances the geological mining industry informationization advancement vigorously, Realization information sharing, may enhance the office efficiency, the frugal fund, this is enhances the profession technology, the management and the service level way that must be taken. In do the science and technology high speed development 21 st century, whether have the strong message resources, and will use it to become fully decides a national, local or the profession economy high speed development important attribute.

\section{Geological mining industry information platform technology present situation}

Before 2000, the geological prospecting work by the national investment, carries on basically according to the long-term regional planning, extremely little appears compares the unit to establish a separatist regime, the information blockade, the repetition investment work situation, In the fund and in the manpower physical resource disposition, the material management, the project management work accounts for the proportion to be low. Along with the prospecting power, the mining right market standardizes gradually, the enterprise and the individual capital expansive inflow, urged to send the geological mining industry market. In processes and so on in material inquiry, initiating a project examination, ore power establishment, ore power transfer, mining industry development, region and organization limit [1], The enterprise and the geological prospecting party five, rushes about between the provinces and cities, the time and the fund waste in the wheel and the hotel, the management efficiency was low, delayed the geological mining industry development step. At present technical data work and so on management and application, geology and mining project examination and construction, ore power establishment and transfer, becomes this profession the work key, Depended on the manual management to be already unable to meet the profession need, had to consummate the office automation management system management system, depended on the computer network technology, the development service 
space, served for the region economy development, The realization science and technology information biggest social efficiency and the economic efficiency, carry on the database development, the management and the application, is this profession urgent matter.

In the recent ten years, the computer technology obtained the fast development in our country, the office automation technology progressed by leaps and bounds, the internet already entered each profession and in ordinary hundred common family names. In the geological mining industry domain, various units start to set up internal database management system, has a part of unit to start to carry on the network service foreign, The overall looked that, the interior data bank administration and the network application system development also is at the initial stage. Systematically serves very difficultly in ours routine work, especially in choice work and so on in target area, initiating a project research, field operation construction and ore power confirmation, is unable to help us radically to search the massive earlier period correlation data, creates the technical work to appear many repetition work, the technical level is unable to enhance fast. At present, through the Internet on-line retrieval, and so on geological data, ore power retrieval network services, mainly provides by the national territory resource management department, Provides the service in view of the single item, has the strict limit to the service object, the average consumer cannot inquire the correlation data at will, cannot publish the geological mining industry information freely; Basically has not been possible to provide omni-directionally, the multi-level network service of geological mining industry synthesis service platform[2].

\section{Theory and Technology of Information Platform}

(1) ASP.NET interactive web technology was under the Windows platform website development personnel provides in one kind of use dynamic database the richly colorful content to cause its stand to become a more active way. But has these rich content codes all is actually based on the Web server end, when client side use service does not need to consider its own uses language and tool.

(2) It is the object-oriented programming language, but is not one kind of script, therefore it has object-oriented programming language all characteristics,

For instance: The seal, succession, polymorphism and so on, this have solved ASP this weakness. The seal causes the code logic to be clear, easy to manage, and applies on ASP.NET to be possible to cause the service logic and the Html page separation, How regardless of like this the page prototype does change, the service logic code does not need to make any modification; The succession and the polymorphism cause the code the reusability to enhance greatly, You may through the inheritance the object which has maximum limit protect you beforehand investment.

(3) ASP.NET is one kind of establishment in the general purpose language procedure skeleton, can use in a Web server establishing the formidable Web application procedure. The procedure moves for the first time when the server end carries on the translation, carries out the efficiency large scale enhancement [3].

(4) It can run almost the entire Web application platform. Universal language basic library, message mechanism, data interface processing can be seamless integration into the ASP.NET Web applications.

(5) ASP.NET is a language independent; you can choose one of the most suitable for your language to write your program, or to use a lot of language to write your program, easy to complete transplantation.

(6) Simple and easy to learn, you can use a simple text editor to modify the code.

(7) Highly efficient management: ASP.NET uses a character based, hierarchical configuration system to make your server environment and application settings simpler.

\section{Geology and Mining Survey Localization Technology}

The geology and mining profession survey localization work, during the penetration routine work, with the geological province investigation, the geological prospecting, the ore power establishment, the mining industry development and so on is closely linked. Compares with other profession 
project survey, has many same spots, but also has the big difference.

The geology and mining profession take studies the Earth surface layer and the place encasement as the goal, the research scope from the mining area to the entire Earth, may surmount the national boundary, the continent, has the greatest breadth; In engaged in the geology and mining work, surveys measuring accuracy request lowly compared to the project, Only then tunnel penetration and so on special job requirement precision measuring, so long as achieved generally then satisfies 1 meter to 10 meters precisions requests. Along with the satellite positioning technology development, the profession and the region influence, grasps GPS widely to apply in the geological mining industry domain, the grasping survey localization technology, has become each technical personnel's necessary quality [4].

This information platform bases on the geological mining industry domain, serves in the ordinary geology technical personnel and the mining industry jobholders, take the computer, the database, the network service technology as the foundation, In view of the geological data inquiry, the ore power service, the legal service, the news commentary, the technical service, the talents exchange, the study, the unit recommendation, the mining industry transaction and so on many aspects, provide the synthesis service. In view of the fact that our country's present situation, at present the geological mining industry informationization should face openness, the comprehensive nature, highly effective, the technical nature, the relatedness, the spatiality, the secure direction is developing.

\section{Database System Platform}

Combined with the actual work, focusing on the future, the system must meet the following specific needs:

(1) Construction take the Internet as the link Web database service system, the ordinary populace may link conveniently in the database, provides the foundation service for the geological mining industry domain.

(2) Requests this system easy to operate, the maintenance simply, the expense inexpensive, the connection to be fast, can make the response fast to the data inquiry, simultaneously guarantees the data the integrity, the accuracy.

(3) Guarantees the network connection and the system stability, can all-weather provide the service.

(4) System itself requests enough vigorously and healthily, can satisfy certain rank the safety requirements.

(5) System must implement the jurisdiction management, according to the different user role, provides the corresponding service.

(6) Aims at the geological mining industry domain, provides legal inquiry, technical service, news commentary, ore power inquiry, geological data and so on inquiry foundation services [5].

In order to can satisfy the geological mining industry information platform the movement, after the analysis, the hardware equipment must include:

(1) Running rate is quick, storage capacity big host server;

(2) Economical, the speed moderate, easy to maintain internal local area network;

(3) Can register the network, data-in ordinary computer certain;

(4) Has the firewall function network router;

(5) Internet channel, optical fiber or special line and so on.

The server can move SQL and the ASP.NET operating system, for example: Windows 2000 Advance Server, Windows 2003, Windows 2007 and so on. The server operating system choice to the overall system is very important, it involves the stability. The server operating system choice also needs to consider the hardware platform the shaping. Uses WindowS2000 Advanced Server to take the server, the system should achieve the computer technology personnel to be possible to install, the detachment, the promotion and the maintenance independently. The system should guarantee as far as possible in maintenance, backup or software and hardware promotion expansion period does not interrupt the service. 
The system should have the high feasibility, mainly displays in following several aspects.

(1) System should use the entire Chinese presented in figures and diagrams friendly contact surface completely, and provides convenient, the nimble operation method and the exhaustive on-line help, easy to study easily to use, and reduces the user keyboard entry as far as possible.

(2) System use way should conform to user's custom or use easily the management style which is accepted by the user, the drawing close to user's thinking mode.

(3) Good fault tolerance, carries on the prompt or the confirmation to the important operation, guarantees the user to understand this operation the consequence.

In view of the geological mining industry domain, establishes one based on the Internet network synthesis service system, the essential target is as follows.

(1) Openness: Each student, the technical personnel, the administrative personnel, the average consumer and so on all is authorized to inquire, the publication correlation information, provides the service in view of the ordinary populace.

(2) Service comprehensive nature: Contains the geological mining industry domain as far as possible each aspect, covering work, study, life, research contents and so on.

(3) Inquiry highly effective: Eliminates the region the difference, can through the internet convenience inquiry, find the related information quickly; Can through the office automation, go through the related formalities fast.

(4) Technical nature and authority: Through the scholar, the expert online service, provides study, report appraisal, technical guidance, fundamental research and so on service contents, initiates to strengthen the nation through science and technology .

(5) Relevance: the information of geological prospecting, mining rights, personnel, equipment, resources, environment, etc., is related to the comprehensive analysis.

(6) space: to take the space position as the main line, the project contact, contact, and other units as a link, the loose, complex data effectively organize the integration, the depth of processing, analysis, expand the application depth and breadth, Users can find all the information in a certain area within the shortest time.

This information platform management system user interface, the function module and the logical code and so on use the VB.NET development, After Visual Studio the .NET 2003 translations, provides the internet service through ASP.NET, and links the SQL2000 information platform database system through ADO.NET. According to the service demand and the specification, this information platform management system management system division is several sub-systems:

(1) User management subsystem: responsible for the user registration, the revision, the examination, registers and so on;

(2) Data entry subsystem: responsible for entering various geological mining data to the database;

(3) Data query subsystem: to users provide with information query and view;

(4) Background management subsystem: data processing and business management by the administrator;

(5) Function module subsystem: open to other subsystems, computing or data calls, in particular coordinate conversion module, the calculation process is complex, involving a wide range is the core of functional modules;

(6) Online tool subsystem: provide formula calculation, coordinate conversion, error analysis, statistical analysis, etc.;

(7) File download subsystem: provide common tool the file to download;

(8) Online advisory subsystem: to help users quickly communicate and get the need to help;

(9) The email sending system: provide internal mail sending and receiving function.

The structure of the management system and the correlation is shown in figure 1 . 


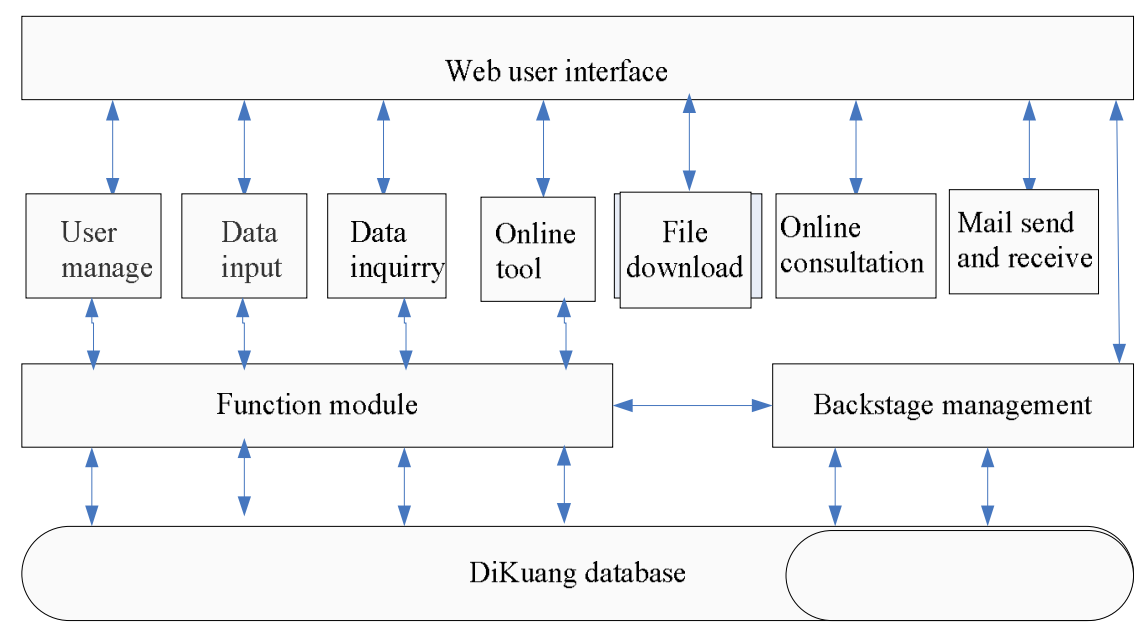

Figure 1.The structure of the management system and the correlation

\section{Conclusion}

Along with our country geology and the mining industry domain fast development, the geological prospecting, the mining industry development and the correlation industry become our country economy development the foundations prop. The construction Internet information service platform, advances the geological mining industry informationization advancement vigorously, is enhances the profession technology, the management level way that must be taken. This paper through discussion the database, the network service and the space orientation technology, in view of the geological data inquiry, the ore power service, the legal service, the technical service, the talents exchange, the mining industry transaction, the unit recommendation, the news commentary and the study and so on many aspects, builds the profession synthesis service platform. In the construction of information platform was solved the following problems. (1) through the geological mining industry domain demand analysis, has determined system hardware platform, operating system platform, database platform and programming language and so on movement environment.(2) Through discussion the database operation, system document management, condition maintenance, data input, data examination, system administration, online tool and so on management processes, The close encompassment data specialization and the relatedness, have completed the information platform construction gradually.

\section{References}

[1] L.M.Zeng, X.B.Wu, Y.H.Liu. The grid computation resources share which based on the semantics and QoS expand jointly, Computer system application. 2009(10)

[2] L.Tang, X.Zhou, H.B.Wang, Y.L. Wang. Multi domain monitoring system for campus grid environment, Journal of Northwestern Polytechnical University. 2009 (04)

[3] L.Wan.Ajax technology in spatial information grid portal on the application research. Software: $2008(11)$

[4] F.D. Li, Ch.L.Li, H.CH.Li, X.Lv. the realization of Geological spatial information metadata service model, geological bulletin. 2008 (05)

[5] X.Y.Zhou, Q.H.Liu. Data grid environment of multi database system, optical disc technology. $2008(02)$ 